\title{
Persistence of distal motor control in the locked in syndrome. Review of 11 patients
}

\author{
I Richard ${ }^{1}$, Y Péreon ${ }^{2}$, P Guiheneu $^{2}$, B Nogues ${ }^{2}$, B Perrouin-Verbe ${ }^{1}$ and JF Mathe ${ }^{1}$ \\ ${ }^{1}$ Service de Rééducation Fonctionnelle, 85 Rue St Jacques, 44035 Nantes, CHRU Nantes; ${ }^{2}$ Laboratoire \\ d'Explorations Fonctionnelles, CHRU Nantes, France
}

\begin{abstract}
We report 11 patients with the locked in syndrome (LIS). The functional outcome was good in four patients with notable motor recovery, but motor deficit remained seriously disturbed in seven patients. All of the patients regained some distal control of finger and toe movements, often allowing functional use of a digital switch. The independence thereby gained is worthwhile, in some patients allowing environment control, communication by means of a computer, and electric wheelchair ambulation. When motor recovery occurs, the progression is disto-proximal with dramatic axial hypotonia. In five patients clinical insomnia was noted and polysomnography showed a reduction of REM sleep. The implications of systems other than the pyramidal tracts in the physiopathology of LIS are discussed.
\end{abstract}

Keywords: tetraplegia; locked-in syndrome; sleep; motor control; brain injury

\section{Introduction}

The locked in syndrome (LIS) is a well defined ${ }^{1,2}$ neurological condition consisting of complete tetraplegia with bilateral facio-glosso-pharyngo-laryngeal paralysis. Communication is only possible through blinking and several authors have insisted that such situations may be unrecognised and that the patients are wrongly considered to be comatose. ${ }^{3-5}$

Pathological material ${ }^{4,6,7,8}$ and magnetic resonance imaging (MRI) data ${ }^{9,10}$ usually show bilateral pontine lesions and the motor syndrome of such patients is usually attributed to bilateral interruption of corticospinal and cortico-bulbar fibers at the pontine level. Long term survival of such patients has been previously reported ${ }^{11,12}$ but the rehabilitation of these patients and the achievement of some degree of independence remains a challenge. Our patients were referred to the same rehabilitation unit between 1983 and 1993. Our study focuses on clinical data with particular interest in the persistence or return of distal motor performance, which was noted in 10 of the 11 patients. This clinical aspect is essential in the choice of rehabilitation strategies, and the successful use of a digital switch was the element that triggered our interest for the analysis of the motor control of these patients.

\section{Methods}

All of the patients presented at some point in their medical history with tetraplegia and bilateral motor involvement of the face, tongue, pharynx and larynx. The patients were conscious and they blinked on demand. The neurological examination was performed by one of the authors, attention being focused on disorder of motor power and of muscle tone;

disorder of eye movements (oculomotor), especially paresis of horizontal gaze;

disorder of sensation; and

the existence of sleep abnormalities, especially of clinical insomnia.

In four patients polysomnographic recordings were performed during one night, including monitoring of the electroencephalogram, chin electromyogram, eye movements, electrocardiogram (V2), respiration, and oxygen saturation. Each $30 \mathrm{~s}$ epoch of data was visually classified as quiet sleep without slow wave sleep (SWS) (stages 1 and 3), or with SWS (stages 3 and 4), rapid eye movement sleep (REM), or wakefulness (W) according to the criteria defined by Rechtsaffen and Kales. ${ }^{13}$

Six patients had MRI. Angiographic investigations were also performed in six cases.

\section{Results}

The age of the 11 patients, at the onset of the LIS ranged from 17 to 73 years, with nine males and two females. The onset was always sudden in patients who were previously in good health. The follow-up ranged from 7 months to 10 years. Two patients died at the ages of 57 and 78, 1 and 5 years after the onset of the LIS. In 10 instances the LIS was of vascular origin; in five cases the angiograms showed occlusion of the basilar artery. The last patient had sustained a severe head injury in a traffic accident. Neurological examination after the return of consciousness revealed a complete LIS. Angiography of both carotids and both 
vertebral arteries was normal and the most probable aetiology was direct contusion of the brainstem.

\section{Clinical data, motor outcome (Table 1)}

Our inclusion criteria were the existence of tetraplegia, defined as the inability to move any limb against gravity, and of bilateral involvement of the face, tongue, pharynx and larynx with mutism. According to Bauer's classification ${ }^{14}$ three subgroups can be distinguished in this population; two with incomplete LIS retaining some amount of voluntary movement, eight with classical LIS and one with a complete LIS. Depending on the motor outcome, we will consider two subgroups. Seven patients (1-7) retained major deficit and remain totally dependent. The follow-up of this group ranges from 6 months to 8 years. These patients fall into groups one and two (minimal or no recovery) as defined by Patterson and Grabois. ${ }^{15}$ Four patients (7-11) achieved notable recovery of motor function, allowing independent gait in three and upper limb function for manipulation and intelligible speech in four patients. These patients fall into groups 3 and 4 of the Patterson and Grabois classification, and may be considered as having a transient LIS.

\section{Chronic LIS (patients 1-7)}

The most outstanding clinical feature in this group with chronic LIS is the return, in all cases before the 6th month of evolution, of minimal distal movements, which are undoubtedly voluntary, can be repeated on the examiner's order and are precise without syncinesias. Such motor control can be limited to one finger or toe or can involve several muscles. All of the patients in this group had brisk tendon reflexes and extensor plantar reflexes. Stretch reflexes, ranged from normal (patients $2,4,7$ ), to clearly exaggerated (patients 3,5 ).

Four of the seven patients have uncontrolled emotional facial expression. Four patients recovered some control of tongue and pharynx movements but none was able to phonate. Paresis of lateral gaze was noted in three patients and multilateral nystagmus in two.

Table 1 Population

\begin{tabular}{|c|c|c|c|c|c|c|c|c|}
\hline Patient & Age & Sex & Aet & $\begin{array}{l}\text { Initial motor } \\
\text { status }\end{array}$ & $\begin{array}{l}\text { Bauer } \\
\text { classification }\end{array}$ & Evolution & $\begin{array}{l}\text { Follow-up } \\
\text { (years) }\end{array}$ & $\begin{array}{l}\text { Motor recovery } \\
\text { (Patterson) }\end{array}$ \\
\hline 1 & 67 & $\mathbf{M}$ & $\mathrm{V}$ & $\begin{array}{l}\text { Blink } \\
\text { Normal gaze }\end{array}$ & Classic & $\begin{array}{l}\text { L up limb mvt } \\
\text { Deglutition } \\
\text { Head rotation }\end{array}$ & 3 & Minimal \\
\hline 2 & 72 & $\mathbf{M}$ & V & $\begin{array}{l}\text { Blink } \\
\text { Vertical gaze }\end{array}$ & Classic & $\begin{array}{l}\text { Distal mvts } \\
\text { Deglutition } \\
\text { Head rotation } \\
\text { Died } 5 \text { years }\end{array}$ & 5 & Minimal \\
\hline 3 & 57 & $\mathbf{M}$ & V & Blink & Total & $\begin{array}{l}\text { None } \\
\text { Died } 1 \text { year }\end{array}$ & 1 & Minimal \\
\hline 4 & 24 & $\mathbf{M}$ & V & $\begin{array}{l}\text { Blink } \\
\text { Vertical gaze }\end{array}$ & Classic & $\begin{array}{l}\text { Distal mvts } \\
\text { Deglutition } \\
\text { Head rotation }\end{array}$ & 8 & Minimal \\
\hline 5 & 17 & $\mathbf{M}$ & $\mathrm{T}$ & $\begin{array}{l}\text { Blink } \\
\text { Vertical gaze }\end{array}$ & Classic & $\begin{array}{l}\text { Distal mvts } \\
\text { Head rotation }\end{array}$ & 3 & Minimal \\
\hline 6 & 74 & $\mathbf{M}$ & $\mathrm{V}$ & $\begin{array}{l}\text { Blink } \\
\text { Vertical gaze }\end{array}$ & Classic & $\begin{array}{l}\text { Distal mvts } \\
\text { Head rotation }\end{array}$ & 0,6 & Minimal \\
\hline 7 & 67 & $\mathbf{M}$ & V & $\begin{array}{l}\text { Blink } \\
\text { Normal gaze } \\
\mathrm{R} \text { hand mvt }\end{array}$ & Incomplete & & 0,5 & Minimal \\
\hline 8 & 30 & $\mathrm{~F}$ & $\mathrm{~V}^{*}$ & $\begin{array}{l}\text { Blink } \\
\text { Vertical gaze }\end{array}$ & Classic & $\begin{array}{l}\text { Up limb mvt } \\
\text { Deglutition } \\
\text { Phonation }\end{array}$ & 9 & Moderate \\
\hline 9 & 24 & $\mathrm{~F}$ & $\mathrm{~V}^{*}$ & $\begin{array}{l}\text { Blink } \\
\text { Vertical gaze } \\
\text { L up limb mvt }\end{array}$ & Incomplete & $\begin{array}{l}\text { Gait } \\
\text { Deglutition } \\
\text { Phonation }\end{array}$ & 10 & Good \\
\hline 10 & 22 & $\mathbf{M}$ & $\mathrm{V}^{*}$ & $\begin{array}{l}\text { Blink } \\
\text { Vertical gaze }\end{array}$ & Classic & $\begin{array}{l}\text { Gait } \\
\text { Deglutition } \\
\text { Phonation }\end{array}$ & 2 & Good \\
\hline 11 & 44 & $\mathbf{M}$ & $\mathrm{V}^{*}$ & $\begin{array}{l}\text { Blink } \\
\text { Vertical gaze }\end{array}$ & Classic & $\begin{array}{l}\text { Gait } \\
\text { Deglutition } \\
\text { Phonation }\end{array}$ & 2 & Good \\
\hline
\end{tabular}

Age at the onset of LIS, sex, aetiology (Aet) of the LIS (traumatic (T) or vascular with $\left(\mathrm{V}^{*}\right)$ or without (V) arteriographic confirmation, initial status, duration of follow-up and motor outcome of the eleven patients 
One patient (4) had undoubtedly voluntary blinking but very poor reflex blinking and no ocular movement in any direction. Vertical paralysis and/or visual disorder probably existed but communication did not allow better study. Sensory loss was found once (right thermo-algic hypoaesthesia).

In three patients nocturnal insomnia was dramatic without diurnal naps nor any complaint of the lack of sleep.

Independence for vital functions was variable in this group. All patients but one (5) became completely independent for respiration. Four were capable of swallowing. Gastrostomy tubes were inserted in the three other patients. All of the patients recovered micturition control. Initial retention was observed twice. In the other patients, systematic indwelling catheterisation did not permit conclusions to be made about the initial status of micturition. Normal micturition returned within some weeks. Independent mobilisation was achieved in one patient using an electrical wheelchair equipped with an occipital joystick and two lateral head switches for direction (backward, forward). All of the patients remain completely dependent for manipulation except for triggering a switch. Three patients used a head switch to trigger a simple environment control device. In four patients the distal finger movements observed were sufficient to reliably trigger a switch attached to a finger ring. In two patients (5 and 2) this allowed functional use of environmental control devices (controlling light, TV, radio, emergency call). In the other patients functional use was reduced to an emergency call.

All of the patients were at first dependent on the use by the observer of a yes-no code for communication. Four patients were able to trigger a switch and be motivated for elaborate communications. Three of them, hospitalized before 1988, used a simple spelling system, implemented on an Apple II E computer. The last patient successfully used an ordinary microcomputer with a commercially available keyboard access software (Handikey Sermia IBM, Issyles Moulineux, France), but finally preferred an electronic typewriter with a vocal synthesis (Communicator Canon, Proteor Dijon, France). Three patients live in nursing homes, the four others have returned home and the primary carer is a member of the family. The following case report highlights the clinical data of this group.

\section{Case report}

On 13 March 1991 patient 5 sustained a severe head injury in a traffic accident. The initial Glasgow score ${ }^{16}$ was 3 . The patient was intubated and placed on artificial ventilation. On the fifth day, ocular pursuit was noted. Neurological examination showed that he blinked on demand. A communication code was established and the patient was recognised as being conscious. Tetraplegia was present, and absence of voluntary control of head movements. Voluntary control of head rotation and neck flexion and extension reappeared, allowing the use of an occipital joystick to drive a wheelchair, and of a chin joystick to play video games. As daytime activity increased, nocturnal ventilation became necessary. Well controlled dissociated left thumb and index movements also reappeared allowing the triggering of a switch for environmental control (James device Siemens, Neuchatel, Switzerland), and communication by the use of an electronic typewriter and a vocal synthetizer (Communicator Canon). Deglutition remained impossible and a gastrostomy tube was inserted. After 2 years in our unit, the patient returned to his parent's home where he has lived for 18 months, without any notable complication.

\section{Transient LIS (patients 8-11)}

Four patients had moderate or good recovery. One presented at the onset with an incomplete LIS. The motor status after 1 year was a right hemiplegia with poor control of the upper limb extensors, exaggerated stretch reflexes of the upper limb flexors and the lower limb extensors, and a left cerebellar syndrome. The three other patients had more unusual patterns of recovery, with early return of distal motor control as in the previous group, and distal-proximal progressive evolution. In these three patients axial hypotonia was considerable, and clearly limited the independence of one patient who had achieved satisfactory limb control. All four patients showed some degree of exaggeration of stretch reflexes. All have regained speech and deglutition. Paresis of horizontal gaze was noted in three patients and insomnia in two.

\section{Case report}

Case 10 is typical of the evolution of these patients. This patient was found unconscious in front of the television on 13 November 1992. He was admitted to an intensive care unit. After sedative medication was discontinued, neurological examination showed complete LIS with total paralysis of lateral gaze and right eye divergence at rest. During the 2nd week, voluntary movements reappeared in all of the left lower limb muscle groups and in the upper limb distal groups (flexion and extension of the fingers and wrist). The use of a TV zap was possible. During the following year, motor recovery occurred, following a distalproximal progression. Strength and control were better on the left side. Axial hypotonia was dramatic and was the limiting factor in the recovery of a functional gait. He was discharged home after 18 months in our unit, and had become intelligible although dysarthric. Gait was possible for long distances without the use of crutches. Independence was complete for all activities. The patient has not returned to work.

\section{Polysomnographic data}

Polysomnographia was performed in five patients, three times in chronic patients, (4-6) once during the evolution of the illness (10) and once after satisfactory motor function had returned (11). The results are summarised in Table 2. One patient showed reduction of total sleep time with a preservation of the proportion of stage 3 and 4 SWS and of REM.

The other four patients also showed a reduction of total sleep time but have abnormal sleep patterns with a reduction of stage 3 and 4 SWS and of REM sleep. These abnormalities are dramatic in two patients, but are less marked in the other two. 
Table 2 Polysomnographic data

\begin{tabular}{cccc}
\hline Patient & Total sleep time & $\%$ SWS & $\%$ REM \\
\hline 4 & 3 h $40 \mathrm{~min}$ & & $24 \%$ \\
5 & 6 h $16 \mathrm{~min}$ & $9.3 \%$ & $11.5 \%$ \\
6 & 3 h 39 min & $1.6 \%$ & $2 \%$ \\
10 & 4 h 53 min & $5.6 \%$ & $3.5 \%$ \\
11 & 6 h 39 min & $13.2 \%$ & $10.3 \%$ \\
\hline
\end{tabular}

$\%$ of SWS (stage $3+4$ Rechtsaffen ${ }^{13}$ ) and \% of REM sleep

\section{Imaging}

Conventional X-ray scans were performed in 10 patients; in three, abnormalities of the brainstem were discovered (hyperdensity once and ischaemic hypodensity twice). One patient presented with acute hypodrocephalus due to the coexistence of brainstem oedema and of an Arnold-Chiari malformation. In the six other patients the X-ray scans were considered to be normal.

Six patients $(5-8,10,11)$ had MRI studies. Pontine lesions were present in all of them, but of variable extension. In one case (11) the hypersignal extended posteriorly and medially to the floor of the fourth ventricle. In patient number $10 \mathrm{MRI}$ showed the extension of the lesion to the inferior cerebellar cortex.

Cerebral angiography was carried out in five patients, and angio-MRI in one. In five patients these investigations revealed the presence of thrombosis of the basilar artery (Figure 1) extending in one patient (10) to the two superior cerebellar arteries. It should be noted that angiography of both carotids and both vertebral arteries was normal in the patient who had a head injury, excluding traumatic vertebro-basilar dissection or thrombosis. The MRI study showed two punctuate pontine hypersignals which appeared to be primarily traumatic (Figure 2).

\section{Discussion}

Diagnosis and prognosis of LIS

The diagnosis of LIS can be easily missed if voluntary blinking is not carefully looked for in patients who otherwise are apparently unconscious. Ocular movements are usually tested horizontally but not vertically in the routine examinations of comatose patients and will be considered to be absent if lateral gaze paresis exists. There is even greater difficulty if vertical paresis or visual impairment exist as was the case in the patient reported by Larmande, ${ }^{17}$ or in our patient 4 .

The most frequent aetiology is basilar artery thrombosis, being the reason in 10 out of our 11 patients, with angiographic evidence in five cases; and in 91 of the 139 cases reviewed by Patterson. ${ }^{15}$ Other aetiologies have been previously reported: brainstem hemorrhage, ${ }^{15}$ centro-pontine myelinolysis, ${ }^{18}$ infectious disease. ${ }^{11}$ Previously reported traumatic LIS $^{15,19,20,21}$ is usually of vascular origin from traumatic dissection or thrombosis of the vertebro-basilar axis. The case of our

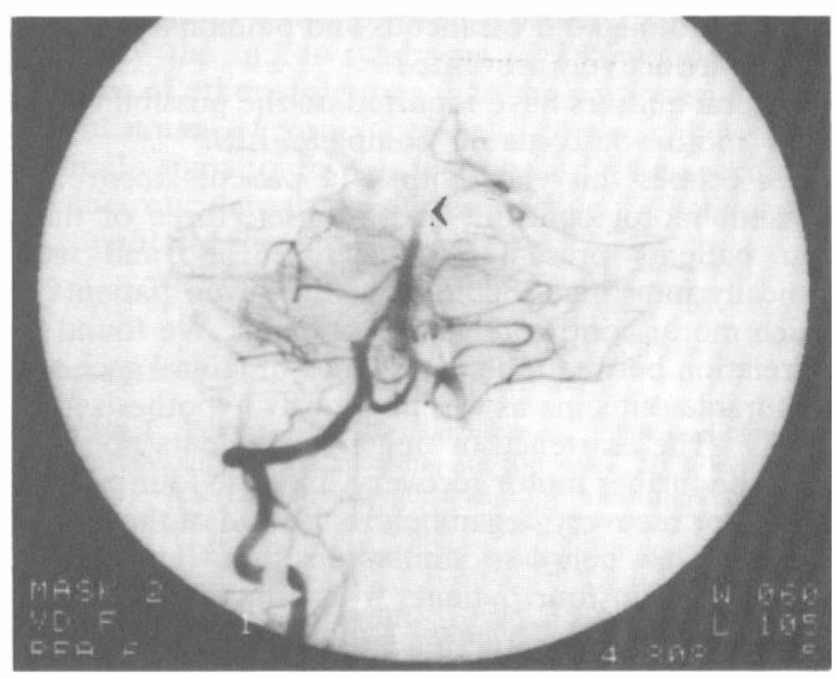

Figure 1 Thrombosis of the basilar artery (patient 10)

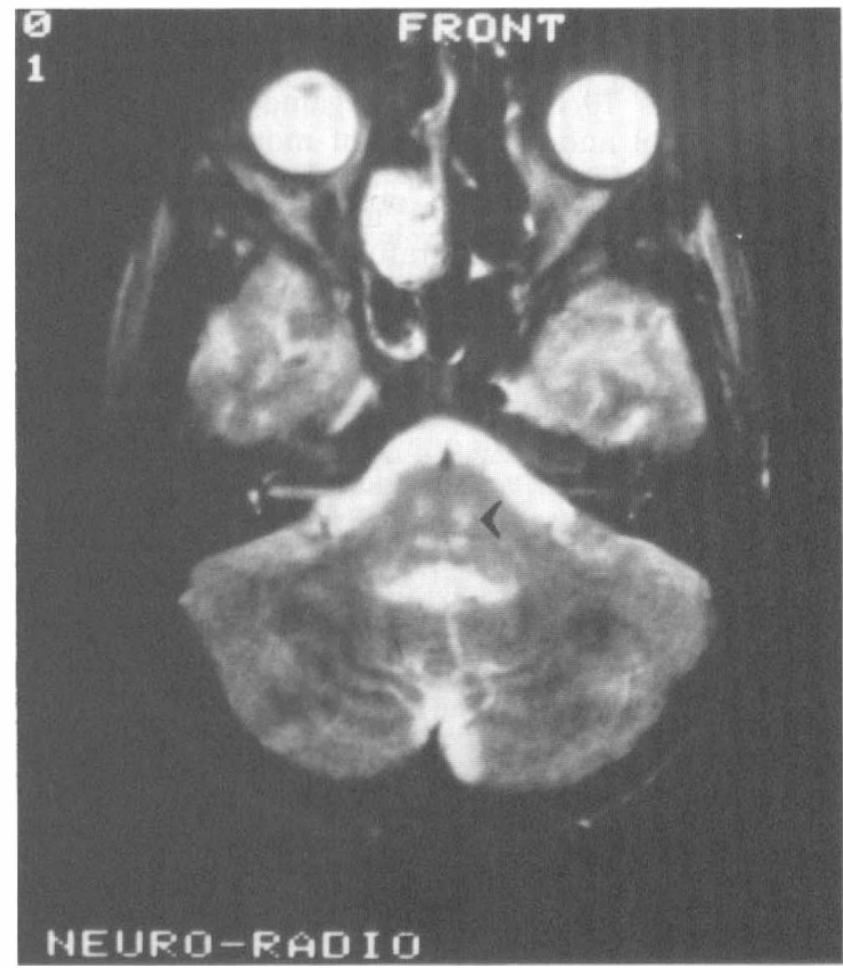

Figure 2 Traumatic lesion of the pons (patient 5)

patient 5 stresses the possibility that direct pontine contusion may also be responsible for a LIS. The danger in the context of a severe head injury, is to fail to recognise the return of consciousness.

The severity of a vital prognosis has been well documented in the literature $(79 / 139$ deaths within the first year in Patterson's series)..$^{15}$ The low mortality in our series is due to the bias induced by the selection of patients referred to a rehabilitation unit. Our data however suggest that after the acute period, survival 
644

may be prolonged if cutaneous and pulmonary complications are actively prevented. ${ }^{12}$

Several authors have reported on the possibility of a good motor outcome in complete LIS. ${ }^{19,20,22,23}$ Our series echoes this view with $4 / 11$ patients recovering efficient motor control. At the onset, three of these four patients presented with total LIS, and were clinically indistinguishable from the seven patients in which motor control remained minimal. We found no correlation between the persistence of lateral gaze and favourable outcome as was previously hypothesized by Yang. ${ }^{10}$ The existence of finger movements does not preclude further motor recovery. In these four patients the motor recovery began before the end of the second month. This delay is similar to that reported by Maccusker ${ }^{22}$ in four patients with a favourable motor outcome (1 week, 7 weeks, 2 months, 10 weeks) and the prognosis of LIS remaining almost complete at the third month of evolution is probably poor. When motor recovery does take place, as patients 10 and 11 show, it may progress for over a year.

\section{Motor control in LIS}

In our series 10/11 patients regained precise distal motor control and the course of motor recovery, in three of the four cases in which it occurred was distal-proximal. This has not, to our knowledge, been previously reported, but careful analysis of previously published cases does indicate a similar pattern although it was not commented upon by their authors.

Maccusker ${ }^{22}$ reports three patients with LIS who had a favourable outcome with the return of motor function first in hand and toes. In one patient the quality of the distal motor control was explicit. In one of their six personal cases Patterson and Grabois ${ }^{15}$ reported the persistence in a patient with an otherwise complete LIS of voluntary flexion and extension of the index finger. Oksenberg $^{24}$ incidentally noted the persistence of thumb movements allowing the triggering of a switch. Markand ${ }^{25}$ reports, without further detail, the persistance of 'hand movements' in four of his seven patients. This clinical feature seems thus fairly characteristic of LIS.

When the LIS remains almost complete the challenge is to make the best use of these minimal voluntary movements and achieve maximal independence. The existence of distal well controlled movements often allows the triggering of a digital switch for the use of environmental control or for communication devices. The independence thereby obtained may be worthwhile, and we believe that such patients should be referred to rehabilitation units. Many commercially available devices exist. For such patients, dependent for the positioning of the switch itself, communication and environment control functions should be incorporated on the same device. This leaves the possibility of using the remaining head control to drive a wheelchair. We do not have the experience of gaze controlled devices, nor of head driven mouse-emulators but in the future they may be valuable alternatives for such patients.
In the four patients with a favourable motor outcome, the recovery of motor function was distalproximal. Marked axial hypotonia was the second prominent clinical feature and these patients did not resemble tetraplegia of spinal origin or bilateral hemiparesia. We believe that physiotherapy for such patients should focus mainly on balancing exercises, with extensive matwork. In our experience the control of spasticity is not as problematic as it is in other upper motor neuron diseases. Occupational therapy should focus on the use of distal motor control for manipulations. Suspension devices are necessary as long as correct elbow and shoulder control are insufficient. These findings also raise more fundamental questions concerning the physiopathological substratum of LIS. LIS is usually interpreted as bilateral interruption, at the pontine level, of cortico-spinal and cortico-nuclear fibres. ${ }^{9,6,26,27}$ In this hypothesis, the clinical features reported here, namely distal motor control, limited spasticity and axial hypotonia are rather surprising, albeit previously noted by other authors. ${ }^{15,22,24,25}$ The view of LIS as bilateral pyramidal tract interruption is probably an oversimplification, and other structures may be involved. At the pontine level, the pyramidal tract is intermingled with the grey matter of the cerebellar nuclei, ${ }^{28}$ which probably suffers ischaemia before the myelinated fibres. Cerebellar involvement may to some extent explain the hypotonia. The exact projections of the reticulo-spinal pathways are unknown, but seem predominantly distributed to axial and proximal motor neurons. ${ }^{28,29}$ Interruption of either cortico-reticular or reticulo-spinal pathways may thus also play a role in the axial and proximal deficit. Preservation of distal motor control may be due to partial sparing of pyramidal fibres. Rubro-spinal fibres, located in the pons dorsal to the pyramidal tract ${ }^{28}$ could also play a role in the remaining control of distal finger movements. . $^{30,31,32}$

\section{Sleep disorder}

We have found in the literature ten examples of LIS with polysomnographia, reported by Oksenberg (one case), ${ }^{24}$ Markand (seven cases) ${ }^{25}$ and Cummings (two cases). ${ }^{33}$ Abnormalities were found in six patients with a diminution of total sleep time and a dramatic reduction of REM sleep and stage 3 and 4 SWS. The same abnormalities were found in four of our five patients. Similar findings have been reported by Guilleminault $^{34}$ and Lavie $^{35}$ in patients with focal pontine lesions.

The localisation of the brainstem structures involved in the genesis of REM sleep has been extensively studied in mammals, especially in the cat. ${ }^{36,37}$ One interesting paradigm is to perform complete transections of the brainstem, at various levels and monitor rostral (EEG) and caudal signs of REM (atonia, vegetative disregulation). Concording results indicate the crucial role of the lateral part of nucleus reticularis oralis in the pontine reticular formation, in the genesis of both rostral and caudal aspects of REM sleep. ${ }^{36,37,38}$ 
Microsurgical destruction of a smaller, more ventral group of neurons leads to the emergence of REM sleep without atonia ${ }^{39}$ and with active motor behaviour, especially hunting behavior in the cat. ${ }^{40}$ Thus these data clearly localise in the pontine reticular formation structures critical for the genesis of REM sleep in its cortical (EEG) and peripheral (atonia) aspects. The projection pathways underlying both aspects are unknown.

The reduction or absence of REM in LIS is thus probably not fortuitous but is related to the pontine lesion itself, and two different interpretations can be proposed. Firstly we could hypothesise that the reticular structures generating REM have been destroyed by the lesion; the second hypothesis, is that the reticular structures responsible for the generation of REM have been disconnected from their cortical targets, interrupting the expression of the cortical features characteristic of REM. Indeed the absence of REM sleep reported by previous authors and noted in our patients is in fact an absence of EEG signs of REM. Indeed EMG data such as chin tonus record are not necessarily of unequivocal analysis in this context, and 'caudal' vegetative signs such as heart rate irregularities or temperature changes are not routinely monitored. This hypothesis could perhaps be corroborated by the data published by Feldman ${ }^{41}$ describing in one LIS patient a total absence of EEG phases of REM sleep, but the existence during EEG phases of slow wave sleep of rapid eye movements on the oculography records. If the absence of REM sleep could be due to the disconnection of REM generator from its cortical targets, rather than to its destruction, we could further hypothesise that the active atonia normally generated during REM sleep could remain or even increase, being disconnected from the structures responsible of its chronobiological regulation. LIS syndrome could thus be considered as a particular arousal stage consisting of atonia without sleep, as opposed to sleep without atonia as described by Jouvet. In this hypothesis which remains as yet difficult to test, could one imagine that such active atonia could be receptive to pharmacological treatment?

\section{Conclusions}

LIS is uncommon but its incidence may increase with the evolution of intensive neurological care. The motor deficit is characterised by complete tetraplegia, bilateral involvement of the face, tongue, pharynx and larynx, but in many patients there is a return of some distal dissociated movements. This feature should be carefully investigated since it dramatically modifies the functional outcome and allows easier use of environmental control and communication devices. Besides this functional aspect, the theoretical implications have been discussed. If the tetraplegia of LIS is due to bilateral interruption of cortico-spinal tracts, the functional role of other structures, such as the corticorubro-spinal tract, in the control of single digit is more important than is usually believed and may be revealed by a bilateral lesion of the cortico-spinal tract. Alternatively the motor syndrome of LIS may be due to lesions of other structures than the cortico-spinal tract. Involvement of cortico-cerebello-cortico circuits and of reticulo-spinal pathways is probable. The specific role of the reticular structures responsible for active atonia during REM sleep is also discussed.

\section{References}

1 Plum F, Poesner JB. The Diagnosis of Stupor and Coma. FA Davis Company: Philadelphia, 8th edn, 1987, pp 8-9.

2 Virgile RS. Locked in syndrome. Case and litterature review. Clin Neurol Neurosurg 1984: 86: 275-279.

3 Pearce JMS. The locked in syndrome. BMJ 1987: 294: 198-199.

4 Gallo UE, Fontanarosa PB. Locked in syndrome: Report of a case. Am J Emerg Med 1989; 7: 581-583.

5 Delacour JL et al. Le syndrome de verrouillage. Ann Fr Anesth Réanim 1988; 7: 433-436.

6 Hawkes CH. 'Locked-in' syndrome: Report of seven cases. BMJ 1974; 4: 379-382.

7 Dehaene I, Dom R, Martin JJ. Le syndrome locked-in. Etude clinique de dix cas. Acta Neurol Belg 1984; 84: 12-20.

8 Nordgren RE, Markesbery WR, Fukuda K, Reeves AG. Seven cases of cerebromedullo-spinal disconnection: The locked-in syndrome. Neurology 1971; 21: 1140-1148.

9 Dollfus $\mathrm{P}$ et al. The locked-in syndrome: A review and presentation of two chronic cases. Paraplegia 1988; 28: 5-16.

10 Yang CS, Lieberman V, Hong CZ. Early smooth horizontal eye movement: A favorable prognostic sign in patients with lockedin syndrome. Arch Phys Med Rehabil 1991; 70: 230-232.

11 Thadoni VM et al. 'Locked-in' syndrome for 27 years following a viral illness: clinical and pathological findings. Neurology 1991; 1: 498-500.

12 Haig A, Katz RT, Sahgal V. Mortality and complications of the locked-in syndrome. Arch Phys Med Rehabil 1987; 68: 24-27.

13 Rechtschaffen A, Kales A. A Manual for Standardised Terminology, Techniques and Scoring System for Sleep Stages of Human Subjects. UCLA Bis: Los Angeles, 1968, pp 2-11.

14 Bauer G, Gerstenbrand F, Rumpl E. Variables of the locked in syndrome. J Neurol 1979; 221: 77-91.

15 Patterson JR, Grabois M. Locked-in syndrome: A review of 139 cases. Stroke 1986; 17: 758-764.

16 Teasdale G, Jennett B. Assessment of impaired consciousness. A practical scale. Lancet $1974 ; 11: 81-84$.

17 Larmande P, Henn D, Jan M, Elie A, Gouaze A. Abnorma vertical eye movements in locked-in syndrome. Ann Neurol 1982; 11: 100-102.

18 Daverat $\mathrm{P}$ et al. Myelinolyse centropontique après transplantation hépatique. Rev Neurol 1992; 148: 687-691.

19 Cabezudo JM, Olabe VB, Lopez-Anguera A, Bacci F. Recovery from locked in syndrome after posttraumatic bilateral distal vertebral artery occlusion. Surg Neurol 1986; 25: 185-90.

20 Bivins D, Biller J, Wayne Laster D, McLean WT. Recovery from posttraumatic locked-in syndrome with basilar artery occlusion. Surg Neurol 1981; 16: 230-234.

21 Orenstein M, Real P, Stierle F, Fuchs C. Locked in syndrome post-traumatique d'installation retardée; Cahiers d'Anesthesiologie 1990; 38: 87-90.

22 MacCusker E, Rudick RA, Honch GW, Criggs RC. Recovery from the 'locked-in' syndrome. Arch Neurol 1982; 39: 145-147.

23 Dupont $\mathrm{C}$ et al. Locked in syndrome: Reinsertion sociale et familiale. A propos de huit cas. Ann Réadapt Méd Phys 1992; 35: $89-101$

24 Oksenberg A, Soroker N, Solzi P, Eider-Groswasser IR. Polysomnography in locked in syndrome. Electroencephalogr Clin Neurophysiol 1991; 78: 314-317.

25 Markand ON, Dyken ML. Sleep abnormalities in patients with brainstem lesions. Neurology 1976; 26: 769-776.

26 Lie Gan Chia. Locked in syndrome with bilateral midbrain 
infarcts. Neurology 1991; 41: 445-446.

27 Reznik M. Neuropathology in seven cases of locked in syndrome. J Neurol Sci 1983; 60: 67-78.

28 Brodal A. Neurological Anatomy in Relation to Clinical Medecine. Oxford University Press, 1981, pp 185-194.

29 Brooks VB. Supraspinal control. In: Brooks, The Neural Basis of Motor Control. Oxford University Press: Oxford, 1986, pp 82-110.

30 Cheney PD, Mewes K, Widener G. Effects on wrist and digit muscle activity from microstimuli applied at the sites of rubromotoneuronal cells in primates. J Neurophysiol 1991; 66: 1978-1991.

31 Fromm C. Contrasting properties of pyramidal tract neurons located in the precentral or postcentral areas and of cortico rubral neurons in the behaving monkey. In: Desmedt JE (ed). Motor Control Mechanisms in Health and Disease. Raven Press: New York, 1986, pp 329-346.

$32 \mathrm{Ghez}$ C. Introduction to the motor systems. In: Principles of Neural Sciences, 3rd edn. Elsevier: Amsterdam, 1991, pp 533-547.

33 Cummings JL, Greenberg R. Sleep patterns in 'locked-in' syndrome. Electroencephalogr Clin Neurophysiol 1977; 43: $270-271$.

34 Guilleminault C, Cathala JP, Castaigne P. Effect of 5Hydroxytryptophan on sleep of a patient with a brain stem lesion. Electroencephalogr Clin Neurophysiol 1973; 34: 177-184.

35 Lavie $\mathrm{P}$ et al. Localized pontine lesion: Nearly total absence of REM sleep. Neurology 1984; 34: 118-120.

36 Siegel JM. Mechanisms of sleep control. J Clin Neurophysiol 1990; 7: 49-65.

37 Siegel JM, Nienhuis R, Tomaszewski KS. REM sleep signs rostral to chronic transections at the pontomedullary junction. Neurosci Lett 1984; 45: 241-246.

38 Lannes B, Micheletti G. Relations anatomo-fonctionnelles des systèmes moteurs avec les systemes de veille et de sommeil. Neurophysiol Clin 1994; 24: 108-131.

39 Schenkel E, Siegel JM. REM sleep without atonia after lesions of the medial medulla. Neurosci Lett 1989; 98: 159-65.

40 Jouvet M, Delorme F. Locus coeruleus et sommeil paradoxal. C R Soc Biol 1965; 1: 895-899.

41 Feldman MH. Physiological observation in a chronic case of locked-in syndrome. Neurology 1971; 21: 459-478. 